\title{
Effects of hunger level and tube diameter on the feeding behavior of teat-fed dairy calves
}

\author{
M. S. Herskin, ${ }^{* 1}$ F. Skjøth, $†$ and M. B. Jensen* \\ *University of Aarhus, Faculty of Agricultural Sciences, Dept. Animal Health \& Bioscience, Research Center Foulum, Blichers Allé, DK-8830 Tjele, \\ Denmark \\ †AgroTech A/S, Institute of Agro Technology and Food Innovation, Udkærsvej 15, DK-8200 Århus N, Denmark
}

\section{ABSTRACT}

Behavioral changes caused by variation in hunger have a great potential in health monitoring in dairy cattle. The present experiment used 48 Danish Holstein bull calves with a median age of $33 \mathrm{~d}$. We examined the effect of different levels of hunger (reduced, in which calves were fed $1.5 \mathrm{~L}$ of milk via esophageal tube before feeding; increased, in which calves were fed half milk ration at the previous feeding, or control, in which calves were fed normal ration at the previous feeding) on feeding behavior of calves fed via different tube diameters $(6.0,3.0$, or $1.5 \mathrm{~mm})$. Behavior observed during a 40-min period after morning milk feeding on d 7, 9, and 11 of testing is reported. No significant interactions between tube diameter and hunger level on behavior were found. Reduced tube diameter led to increased latency to empty the teat bucket, increased duration of nutritive sucking, and decreased duration of nonnutritive sucking for calves fed via $1.5-\mathrm{mm}$ tubes compared with calves in the 2 other treatments. The duration of nonnutritive sucking increased with increasing level of hunger. Furthermore, calves with reduced hunger showed a lower frequency of butting than calves at the 2 other hunger levels. The present results show that only a rather high reduction in tube diameter led to reduced drinking rate. Neither reduced nor increased hunger levels led to changes in drinking rate, but calves showed reduced nonnutritive sucking and butting when they were less hungry and increased nonnutritive sucking and butting when hunger was increased. The results suggest that nonnutritive sucking is a more sensitive indicator than drinking rate of changes in feeding motivation. Consequently, reduction in nonnutritive sucking might be a new candidate in the search for behavioral indicators of disease in dairy calves.

Key words: butting, calf, hunger, sucking

Received July 8, 2009.

Accepted January 19, 2010

${ }^{1}$ Corresponding author: MetteS.Herskin@agrsci.dk

\section{INTRODUCTION}

Behavioral changes caused by variation in hunger have a great potential in health monitoring in dairy cattle (reviewed by Weary et al., 2009). A lower rate of feeding and a reduction in intake may be expected to be behavioral signs of reduced hunger, but Svensson and Jensen (2007) failed to find effect on these variables as a result of spontaneous disease (diarrhea or respiratory disease with only mildly reduced general condition) among calves fed milk via a computer-controlled milk feeder. A possible explanation for the lack of effect on milk intake may be the restricted milk allowance; Borderas et al. (2009) showed that only calves offered very high milk allowances reduced their intake as a result of disease. A possible explanation for the lack of effect on feeding rate may be that milk flow was so high that even weak or diseased calves could obtain milk at the preferred high rate. Reduced milk flow has been found to reduce rate of ingestion, although calves to some extent could compensate by increasing the vacuum in the oral cavity and maintain drinking behavior despite reduced milk flow (Haley et al., 1998a,b). However, increased hunger may enable calves to overcome effects of reduced milk flow and maintain normal drinking. An opposite effect of reduced hunger might also be expected. Therefore, a certain level of reduction in milk flow may be a prerequisite for rate of ingestion to be a sensitive indicator of health status.

Other key parts of bovine suckling behavior that may be behavioral indices of hunger in calf housing systems are nonnutritive sucking and butting. Calves on restricted milk allowance performed several bouts of nonnutritive sucking following milk ingestion, as opposed to ad libitum fed calves (De Paula Vieira et al., 2008). Furthermore, de Passillé and Rushen (2006) showed that reduced milk availability to calves suckling the dam increased butting of the udder, whereas increasing milk availability had the opposite effect. Nonnutritive sucking and butting have not previously been related to disease. However, assuming that behavioral signs of reduced hunger caused by feeding are comparable to 
signs of reduced hunger caused by disease, we included examination of these behaviors and their responses to variation in hunger.

The present experiment examined effects of hunger level on feeding behavior of calves fed from different tube diameters. The hypotheses were 1) reduced tube diameter results in reduced feeding rate, reduced nonnutritive sucking, and increased butting; 2) calves with reduced hunger compensate less for the reduced tube diameter and therefore have a lower feeding rate and perform less nonnutritive sucking and less butting than control calves; and 3) calves with increased hunger compensate more for the reduced tube diameter and therefore have a higher feeding rate, more nonnutritive sucking, and more butting than control calves.

\section{MATERIALS AND METHODS}

\section{Animals and Feeding}

The present experiment was conducted during spring 2007 and complied with Danish Ministry of Justice law concerning experiments with animals and care of experimental animals.

This experiment was conducted at the cattle research facility of the Faculty of Agricultural Sciences, University of Aarhus (Foulum, Denmark). A total of 48 Danish Holstein bull calves were used as experimental animals. Twenty-three of these were born at the research facility, 7 were born at the Cattle Research Centre nearby (Tjele, Denmark), and 18 were purchased from commercial dairy farms in the area. The calves that were not born at the research facility were brought there on average (mean $\pm \mathrm{SE}$ ) $5.5 \pm 0.7 \mathrm{~d}$ before the start of the experimental period.

Prior to the experimental period, calves had been housed with their dam in straw-bedded pens for a maximum of $24 \mathrm{~h}$ after birth. Thereafter, they were housed in individual straw-bedded pens of approximately 2.3 $\mathrm{m}^{2}$ and offered milk via teat buckets (plastic buckets fitted with 1 teat; Peach Teat, Skellerup Industries Ltd., Christchurch, New Zealand). During the initial 4 d postpartum, calves were offered colostrum ad libitum, and from $\mathrm{d} 5$ and until the start of the experimental period they were offered a daily allowance of $6 \mathrm{~L}$ of whole milk in 2 feedings.

At the start of the experimental period calves were moved in pairs to straw-bedded pens of either $1.9 \times$ $2.2 \mathrm{~m}$ or $2.5 \times 2.2 \mathrm{~m}$. The calves were offered a daily allowance of $6 \mathrm{~L}$ of whole milk in 2 equally sized feedings. Two plastic buckets fitted with 1 teat each (Peach Teat, Skellerup Industries Ltd.) were used for each pen. Calves had ad libitum access to water, hay, and concen- trate (18\% CP; Grøn Kalv Valset, DLG, Copenhagen, Denmark).

All behavioral recordings were conducted during the morning feeding. Before feeding the first calf of each pair, the other calf was moved to an adjacent waiting pen to allow for undisturbed individual feeding and to ensure that behavior of the 2 calves represented independent observations. Milk was provided to the first calf of each pair at $0900 \mathrm{~h}$ and subsequently at 0945 $\mathrm{h}$ to the other calf of the pair, when the first calf was in the waiting pen. Throughout the experiment, the feeding order of the 2 calves was kept constant. During the afternoon feeding (at $1700 \mathrm{~h}$ ), the calves in each pair were fed simultaneously from 2 buckets placed in the resident pen.

\section{Experimental Design}

The experiment was conducted as a randomized complete block design with 4 overlapping blocks of 12 calves. A block is defined as time of insertion into 1 of 6 pens, and the calves were randomly assigned to the pens. Within each block, each pen was allocated to 1 of the following 3 milk tube diameter treatments to be used throughout the experiment: normal milk flow, in which the calves were fed milk from teats with a milk tube diameter of $6.0 \mathrm{~mm}$; slightly reduced diameter, in which the calves were fed milk from teats with a milk tube diameter of $3.0 \mathrm{~mm}$; and largely reduced diameter, in which the calves were fed milk from teats with a milk tube diameter of $1.5 \mathrm{~mm}$.

The median age (25-75\% quartiles in parentheses) of the calves was $33 \mathrm{~d}(30-38 \mathrm{~d})$ at the initiation of behavioral registration and the median weight was 59 $\mathrm{kg}(50-66 \mathrm{~kg})$. Age and BW did not differ between calves assigned to different treatments. The calves were introduced to the experimental treatments and pens on d 0 (start of the experimental period). On d 7, 9, and 11 during morning feeding, behavior was recorded by direct observation using continuous sampling (Martin and Bateson, 2007) for 40 min starting at milk provision. Each observer followed 2 calf pairs, leading to 3 observers present in the barn for each observation day. Overall, 5 trained observers were used during the experiment. An ethogram of the recorded behavior is shown in Table 1. On each observation day, the prefeeding hunger levels of the calves were manipulated into 1 of 3 hunger levels. In this way, after the 3 observation days, each calf had been exposed to all 3 hunger levels once. The order of exposure to the hunger levels were balanced over observation days. The hunger levels were as follows: reduced hunger, in which calves received normal milk the night before and $1.5 \mathrm{~L}$ of whole milk via 
Table 1. Ethogram of calf behavior recorded during the 40-min observation period after provision of milk

\begin{tabular}{ll}
\hline Behavioral variable & Definition $^{1}$ \\
\hline Nutritive sucking & $\begin{array}{c}\text { The calf is sucking the teat with rhythmic movements of the mouth and the tongue } \\
\text { cupped around the teat. There is milk in the bucket. } \\
\text { The calf is sucking the teat with rhythmic movements of the mouth and the tongue } \\
\text { cupped around the teat. The teat bucket is empty. } \\
\text { The calf lowers its head and thrusts it upward with or without the teat in the mouth. }\end{array}$ \\
\begin{tabular}{l} 
Butting directed at teat or teat bucket \\
\hline
\end{tabular}
\end{tabular}

${ }^{1}$ Definitions adapted from Haley et al. (1998b).

esophageal tube before the morning feeding; increased hunger, in which calves received half milk ration the night before and were sham tube fed without liquid before the morning feeding; or control, in which calves were fed normal ration the night before and sham tube fed without liquid before the morning feeding. Tube feeding took place $78 \pm 2$ min (range: $35-115 \mathrm{~min}$ ) before feeding. The calves were tube fed as gently and carefully as possible and always in the same order as the experimental feedings. The duration of tube feeding was not recorded throughout the experiment, but on 1 haphazardly chosen observation day, the duration was recorded for 8 calves as $25 \pm 11 \mathrm{~s}$ (range: $15-44 \mathrm{~s}$ ) from the time the person entered the pen until the tube was in place in the calf's stomach; the tubes were in place for $36 \pm 11 \mathrm{~s}$ (range: $19-58 \mathrm{~s}$ ), and the total duration of the disturbance was $60 \pm 18 \mathrm{~s}$ (range: $44-102 \mathrm{~s}$ ).

\section{Establishing Reduced Tube Diameter}

The reduced tube diameters were achieved by insertion of a 1-cm plastic cylinder (Acetalplast) into the supply pipe of the teats, leaving a diameter of either 3.0 or $1.5 \mathrm{~mm}$ available space for milk flow. For the $6-\mathrm{mm}$ control treatment, the teat was not manipulated. The plastic cylinder was kept permanently in the supply pipes during the experiment and buckets were marked with individual calf numbers, ensuring that the calves were fed the correct milk tube diameter and that the observers were blind to the treatments during the direct observations of calf behavior.

\section{Clinical Examinations}

During the experimental period from d 7 to 18 , all calves were examined clinically on Mondays, Wednesdays, and Fridays as part of another study. The examination included measurements of rectal temperature and feces scores as described by Svensson and Jensen (2007). In the present experiment, calves were classified as diseased when rectal temperatures were greater than $39.5^{\circ} \mathrm{C}$, or feces scores were above 1 (feces of a gruellike or watery consistency), or both. In these cases, the calves were excluded from the observations until no clinical signs of disease were evident, leading to variations in the number of observations on each registration day. The exact numbers of observations are shown in the tables.

\section{Variables}

For each milk tube diameter treatment and hunger level, the following 5 behavioral variables were calculated from the 40-min observation periods: 1) latency to empty the teat bucket (the interval from milk provision until all milk was drunk), seconds; 2) duration of nutritive sucking, seconds; 3) frequency of nutritive sucking; 4) duration of nonnutritive sucking, seconds; and 5) frequency of butting behavior.

\section{Statistical Analysis}

Latencies to empty the teat buckets were regarded as censored variables (Kleinbaum, 1996) and compared using the PROC Lifetest for survival data in SAS (version 8, SAS Institute Inc., Cary, NC). Results are given as medians followed by 25 to $75 \%$ quartiles. The frequency of nutritive sucking and butting was modeled as a Poisson response using PROC GENMOD in SAS (version 8, SAS Institute Inc.). The fixed effects included hunger level, milk tube diameter, the interaction between hunger level and milk tube diameter, identity of the observer ( 5 different persons), observation number $(1,2$, or 3$)$, and interval from tube feeding to observation (intervals $\leq 50 \mathrm{~min}$ vs. intervals $>50 \mathrm{~min}$ ). Furthermore, preexperimental BW was included as a covariate. The durations of nutritive and nonnutritive sucking were analyzed using PROC MIXED of SAS (Littell et al., 2006). The fixed effects model included hunger level, diameter of the milk tube, the interaction between hunger level and tube diameter, identity of the observer (5 different persons), observation number (1, 2 , or 3 ), and interval from tube feeding to observation (intervals $\leq 50$ min vs. intervals $>50 \mathrm{~min}$ ). Furthermore, preexperimental BW was included as a covariate. Observation number $(1,2$, or 3$)$ was included as repeated factor and compound symmetry covariance structure was applied (Littell et al., 2006). Degrees of freedom 
Table 2. Effects of milk tube diameter on calf behavior during the 40-min observation period after provision of milk via teat bucket ${ }^{1}$

\begin{tabular}{|c|c|c|c|c|}
\hline Behavioral variable & \multicolumn{3}{|c|}{ Milk tube diameter (mm) } & $P$-value \\
\hline Latency from milk provision until teat bucket is empty, $\mathrm{s}$ & $659^{\mathrm{a}}(575-2,400)$ & $389^{\mathrm{b}}(254-2,400)$ & $366^{\mathrm{b}}(220-2,400)$ & $<0.001$ \\
\hline Frequency of nutritive sucking ${ }^{2}$ & $13.5 \pm 3.1$ & $5.9 \pm 1.3$ & $6.1 \pm 1.1$ & NS \\
\hline Duration of nonnutritive sucking, s & $104 \pm 17^{\mathrm{a}}$ & $260 \pm 43^{\mathrm{b}}$ & $197 \pm 27^{\mathrm{b}}$ & 0.003 \\
\hline Frequency of butting $^{2}$ & $14.9 \pm 2.8$ & $11.2 \pm 1.9$ & $8.4 \pm 1.2$ & NS \\
\hline
\end{tabular}

${ }^{\mathrm{a}, \mathrm{b}}$ Different superscripts indicate significant difference between milk flow reduction treatments.

${ }^{1}$ Latencies are medians with 25 to $75 \%$ quartiles in parentheses; other variables are means \pm SE.

${ }^{2}$ Number of observations during the 40 -min observation period.

were calculated using the Satterthwaite approximation. Because no significant interactions were found, data are reported as main effects. Results are given as means \pm standard error as well as $\mathrm{F}\left(\mathrm{df}_{\text {treatment }}\right.$, $\left.\mathrm{df}_{\text {error }}\right)$ and the corresponding $P$-values. Throughout the experiment a significance level of 0.05 was chosen, whereas $0.05<P$ $<0.10$ was considered a tendency.

\section{RESULTS}

Because of problems with some calves showing clinical signs of diarrhea and therefore not being observed, the numbers of observations vary (Tables 2 and 3 ).

\section{Interactions Between Tube Diameter and Hunger Level}

No significant interactions between tube diameter and hunger level were found. However, for the frequency of butting, a tendency to an interaction was found $\left(\mathrm{F}_{4,49}=\right.$ $2.30 ; P=0.07 ; \mathrm{n}=9-15)$. Among calves fed via tubes $1.5 \mathrm{~mm}$ in diameter, the calves with increased hunger tended to show more butting behavior compared with the calves with reduced hunger $(20.9 \pm 4.1,13.3 \pm 4.1$, and $12.0 \pm 5.9$ butts during the $40 \mathrm{~min}$ of observa- tion for increased hunger, control, and reduced hunger calves, respectively). For the calves fed via tubes 3.0 $\mathrm{mm}$ in diameter, animals with increased or control hunger tended to respond by increased butting behavior compared with the calves with reduced hunger (13.5 $\pm 3.0,14.2 \pm 3.9$, and $5.6 \pm 2.5$ for increased hunger, control, and reduced hunger calves, respectively). No differences were found for the calves fed via tubes measuring $6.0 \mathrm{~mm}$ in diameter.

\section{Effects of Reduced Tube Diameter on Behavior During and After Milk Provision}

When the diameter of the milk tube was the normal $6.0 \mathrm{~mm}$ or the medium $3.0 \mathrm{~mm}$, the calves emptied the teat bucket within 6.1 to $6.5 \mathrm{~min}$, whereas feeding from a milk tube $1.5 \mathrm{~mm}$ in diameter increased the latency to empty the teat bucket to approximately $11 \mathrm{~min}\left(\chi^{2}\right.$ $=27.5 ; \mathrm{df}=2 ; P<0.001 ;$ Table 2 ).

Until the teat buckets were empty, the calves spent the majority of the time in nutritive sucking. The tube diameter treatments significantly affected the duration of nutritive sucking behavior; calves fed via tubes 1.5 $\mathrm{mm}$ in diameter spent more time in nutritive sucking than calves in the 2 other treatments $\left(\mathrm{F}_{2,27}=6.19 ; P=\right.$

Table 3. Effects of hunger level on calf behavior during the 40-min observation period after provision of milk via teat bucket ${ }^{1}$

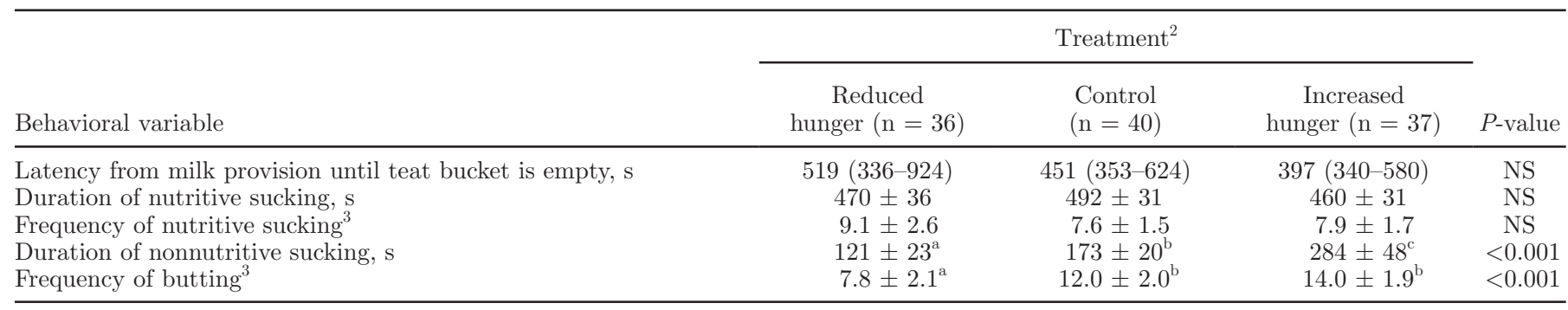

${ }^{\mathrm{a}-\mathrm{c}}$ Different superscripts indicate significant difference between hunger levels.

${ }^{1}$ Latencies are medians with 25 to $75 \%$ quartiles in parentheses; other variables are means $\pm \mathrm{SE}$.

${ }^{2}$ Calves with reduced hunger were fed $1.5 \mathrm{~L}$ of milk approximately $1 \mathrm{~h}$ before observation, controls were fed the normal ration of $3 \mathrm{~L}$ of milk, and calves with increased hunger were given only $1.5 \mathrm{~L}$ of milk the night before.

${ }^{3}$ Number of observations during the 40-min observation period. 
0.006; Table 2). However, no differences were found in the frequency of nutritive sucking.

During the 40-min observation period after the provision of milk, the duration of nonnutritive sucking was affected by the diameter of the milk tubes, showing that feeding via a tube $1.5 \mathrm{~mm}$ in diameter led to a shorter duration of nonnutritive sucking than feeding via the 2 other treatments $\left(\mathrm{F}_{2,28}=7.07 ; P=0.003\right.$; Table 2). No differences between tube diameter treatments were observed for the frequency of butting.

\section{Effects of Hunger Level on the Behavior of Calves During and After Milk Provision}

Hunger level did not affect the latency to empty the teat bucket or the duration or frequency of nutritive sucking (Table 3). The duration of nonnutritive sucking, however, was affected by hunger level, showing that the calves with reduced hunger spent the shortest time in nonnutritive sucking; the control calves were intermediate, and calves with increased hunger spent the longest time in nonnutritive sucking $\left(\mathrm{F}_{2,66}=9.66\right.$; $P<0.001$; Table 3). Furthermore, the different hunger levels affected the frequency of butting; calves with reduced hunger showed a lower frequency than calves of the 2 other hunger levels $\left(\mathrm{F}_{2,39}=11.32 ; P<0.001\right.$; Table 3).

\section{DISCUSSION}

This report presents data on the effects of hunger level and reduced tube diameter on sucking behavior of dairy calves, quantified after more than 1 wk of acclimatization to the milk tube diameters. Reduced tube diameter led to reduced drinking rate, but only for the maximum reduction treatment. A reduction in drinking rate for calves with reduced hunger could not be shown, but while feeding they showed other signs of reduced hunger such as a lower level of butting behavior and a lower duration of nonnutritive sucking. We were not able to show that calves with increased hunger responded by increasing drinking rate, but they did perform increased nonnutritive sucking and tended to perform more butting.

The present experiment tested 3 hypotheses, the formulation of which was based on evidence from earlier studies on calf sucking behavior (e.g., de Passillé and Rushen, 2006). First, we hypothesized that decreased diameter of the milk tubes would lead to reduced feeding rate, reduced nonnutritive sucking, and increased butting. We found a reduced feeding rate, but it was shown only for the calves fed via tubes measuring 1.5 $\mathrm{mm}$ in diameter and not $3.0 \mathrm{~mm}$. Feeding rate may be a relatively robust individual characteristic because of genotype or earlier experiences, and animals may aim at maintaining a preferred feeding rate (Nielsen, 1999). Haley et al. (1998a) showed that calves fed milk can drink slower from a teat than what would flow out by gravity, but that calves drink milk from teat buckets at approximately $1 \mathrm{~L} / \mathrm{min}$, which might correspond to a preferred, or optimal, feeding rate (Nielsen, 1999).

In earlier experiments focusing on feeding rate of calves during milk feeding from teat buckets and manipulating the resistance in the milk tubes, Haley et al. (1998a) used milk tubes ranging in diameter from 1.6 to $5.5 \mathrm{~mm}$, comparable to the present study. As in the present study, Haley et al. (1998a) found increased latency to empty the buckets when the resistance in the tubes was maximal, as well as a shorter duration of nonnutritive sucking. Furthermore, Haley et al. (1998a,b) did not observe differences between intermediate milk tube diameters; only milk tubes less than $2 \mathrm{~mm}$ in diameter seemed to affect the drinking rate. Haley et al. (1998a) concluded that calves to some extent can compensate for an increased resistance. Similar results have been described by Jung and Lidfors (2001) using milk flows of either 0.5 or $1 \mathrm{~L} / \mathrm{min}$ and by de Passillé and Rushen (2006), who were able to show only a weak correlation between measures of sucking behavior and milk intake. As suggested by Haley et al. (1998a), these adjustments are probably achieved by increasing the vacuum in the oral cavity as well as the position and movements of the tongue. We did not systematically record this behavior, but also in the present experiment, the calves fed via the tubes measuring $1.5 \mathrm{~mm}$ in diameter appeared to assume a specific body posture and show specific facial expressions during sucking, characterized by, for example, leaning backward with the cheeks sucked in and the eyes dilated. Recording of such behavior patterns combined with quantification of the oral vacuum would have been valuable and should receive more focus in future investigations.

In the present experiment, not only drinking rate but also the duration of nonnutritive sucking was affected by the diameter of the milk tubes, showing that calves fed via tubes measuring $1.5 \mathrm{~mm}$ in diameter responded with the shortest duration of nonnutritive sucking. Similar results have been shown by Jung and Lidfors (2001) comparing milk flow of 0.5 and $1 \mathrm{~L} / \mathrm{min}$. In a series of experiments, de Passillé and Rushen (1997) showed that calves' motivation for nonnutritive sucking decreases over time since the provision of milk. This means that, irrespective of the opportunity to suck during feeding, calves will not be motivated to suck after approximately $10 \mathrm{~min}$. Our results are in concordance with those of Haley et al. (1998a), who found that the duration of nutritive sucking was longer and the duration of nonnutritive sucking was shorter when calves 
were fed from the smallest orifice size. Furthermore, the duration of nutritive and nonnutritive sucking added up to approximately $10 \mathrm{~min}$ per meal, which has also been described earlier (e.g., Jensen and Budde, 2006). In the present experiment, the median latency to empty the teat bucket for the calves fed from 1.5-mm tubes was approximately $11 \mathrm{~min}$, and the calves may not have been motivated to perform sucking after finishing their meal. Indeed, some calves fed from the $1.5-\mathrm{mm}$ tubes did not empty the teat bucket within the 40-min observation period and were consequently not able to perform nonnutritive sucking.

The second hypothesis of the present study was that reduced feeding motivation would result in reduced effort in overcoming the decreased diameter of the milk tubes and thereby reduce the drinking rate. The present data, using provision of $50 \%$ of the usual allowance approximately $1 \mathrm{~h}$ before feeding, did not confirm this. However, as also expected, the calves with reduced hunger performed less nonnutritive sucking and less butting, supporting that these aspects of milk feeding behavior are affected by feeding motivation in calves. Senn et al. (2000) found a positive correlation between milk intake and postmeal interval and suggested that calves have a postingestion factor involved in postprandial satiety, whereby young calves can regulate milk intake based on time and volume of their last meal. Furthermore, gastric preloading has led to reduced milk intake in other animal species as well [e.g., pigs (Stephens, 1975)]. However, because it has been shown that dairy calves with access to milk ad libitum will drink about $10 \mathrm{~L}$ of milk/d (Jasper and Weary, 2002), the calves with reduced hunger in the present study were not expected to be satiated but merely to have their hunger level reduced. The present control treatment was based on Danish recommendations for milk fed calves and the other treatments as either a $50 \%$ reduction in milk provision in the last meal or provision of $50 \%$ extra milk before the observation meal. However, in the future, it would be relevant to include treatments representing satiety in similar studies.

Despite the relatively small variations in hunger level, the present data show that calves with reduced hunger responded by decreased nonnutritive sucking and butting compared with calves in the 2 other treatments. Decreased sucking behavior after tube feeding has also been described in calves suckling cows (de Passillé, 2001), and the present results support that nonnutritive sucking in calves fed by teat buckets can be reduced when the hunger level is reduced.

The final hypothesis for the present experiment concerned calves with increased hunger. We expected that these calves would put more effort into overcoming the reduction in the diameter of the milk tubes and therefore drink milk at a higher rate than the control calves. This was not found, but the calves with increased hunger had an increased duration of nonnutritive sucking compared with the controls, and calves with increased hunger fed via 3.0- or 1.5-mm tubes showed a higher frequency of butting than the calves fed from $6.0-\mathrm{mm}$ tubes. The existing literature includes mixed evidence for a relation between increased hunger and the duration of nonnutritive sucking after drinking milk in calves. de Passillé and Rushen (1997) did not find any differences between nonnutritive sucking in calves fed a half or a whole meal, whereas calves fed a reduced-size meal were observed to perform increased nonnutritive sucking (Jung and Lidfors, 2001). Even though nonnutritive sucking after provision of milk, as mentioned by de Passillé (2001), appears not to be controlled by hunger alone and seems to be a relatively inflexible response to the taste of milk, the duration of postmilk nonnutritive sucking seems to be an indicator of feeding motivation and has been suggested as a tool for monitoring hunger in calves fed from automatic feeders (De Paula Vieira et al., 2008). The present results seem to confirm this and suggest that the duration of nonnutritive sucking is sensitive toward changes in hunger level, both increasing and decreasing hunger. Reduced nonnutritive sucking may therefore be included as a variable in future investigations of behavioral indicators of disease in calves.

Butting is a key part of bovine suckling behavior (Lidfors et al., 1994), but the present results show no direct relation between butting behavior and diameter of the milk tubes. In contrast, Haley et al. (1998b) observed increased butting when calves were fed from 1.6-mm milk tubes compared with tubes of larger diameters and suggested that butting can be induced by low milk flow-rate. Furthermore, under natural suckling conditions, calf pushing, butting, and switching between teats have been described as behavioral responses toward low or decreasing milk flow (e.g., Lidfors et al., 1994). In the present experiment, the calves did not experience changes in milk flow during the 40-min observations but rather experienced a constant milk flow to which they had been accustomed for at least $7 \mathrm{~d}$. Furthermore, in this study we report the total number of butts observed during the 40-min period, whereas Lidfors et al. (1994) described that butting peaks twice during natural suckling: before milk ejection and in the last part of the sustained rhythmic nutritive sucking. Haley et al. (1998b) described that the effects of reduced milk flow on calf butting behavior were observed in the first 
5 min after milk provision. It is therefore possible that methodological differences can explain the deviating results.

Even though butting behavior is a response toward reduced milk flow, the present results show that the calves with reduced hunger butted less than the calves at the 2 other hunger levels, suggesting that the level of butting can be related to the feeding motivation of the animals. Based on observations of increased butting in fast-drinking calves, Appleby et al. (2001) suggested that increased butting might be an indicator of increased feeding motivation in calves. de Passillé and Rushen (2006) found increased butting in calves fed a reduced milk ration, whereas de Passillé (2001) and de Passillé et al. (1996) were not able to induce changes in butting behavior by decreasing the milk availability. However, the present results support that reduced hunger might be indicated by decreased butting behavior.

In this study we aimed at modeling behavioral consequences of disease (e.g., Johnson, 2002; Dantzer and Kelley, 2007) by experimental manipulation of the hunger level of the calves, knowing that reduced hunger is only one element in the motivational systems underlying sickness behavior (Hart, 1988). However, the results show that the calves with reduced hunger responded by longer duration of nonnutritive sucking and reduced butting behavior during the 40-min observation period compared with the control calves. It is not known whether diseased calves would respond in a similar way.

In conclusion, the present experiment examined aspects of the relation between milk tube diameter, hunger level, and behavior of calves when fed milk from teat buckets. We found that only a rather high reduction in milk tube diameter led to reduced drinking rate. Neither reduced nor increased hunger level led to changes in drinking rate, but calves showed reduced nonnutritive sucking and butting when they were less hungry and increased nonnutritive sucking and butting when hunger was increased. The results suggest that nonnutritive sucking is a more sensitive indicator than drinking rate of changes in feeding motivation. Consequently, reduction in nonnutritive sucking might be a new candidate in the search for behavioral indicators of disease in dairy calves.

\section{REFERENCES}

Appleby, M. C., D. M. Weary, and B. Chua. 2001. Performance and feeding behaviour of calves on ad libitum milk from artificial teats. Appl. Anim. Behav. Sci. 74:191-201.
Borderas, T. F., J. Rushen, M. A. G. von Keyserlingk, and A. M. de Passillé. 2009. Automated measurement of changes in feeding behavior of milk-fed calves associated with illness. J. Dairy Sci. 92:4549-4554.

Dantzer, R., and K. W. Kelley. 2007. Twenty years of research on cytokine-induced sickness behavior. Brain Behav. Immun. 21:153-160.

de Passillé, A. M. 2001. Sucking motivation and related problems in calves. Appl. Anim. Behav. Sci. 72:175-187.

de Passillé, A. M., G. Richer, J. Morrissette, and J. Rushen. 1996. Quantity of milk in the udder, the level of hunger, and sucking behaviour of the nursing calf. Page 58 in Proc. 30th Int. Congr. ISAE, Guelph, Ontario, Canada. The Colonel KL Campbell Centre for the Study of Animal Welfare, Guelph, Canada

de Passillé, A. M., and J. Rushen. 1997. Motivational and physiological analysis of the causes and consequences of non-nutritive sucking by calves. Appl. Anim. Behav. Sci. 53:15-31.

de Passillé, A. M., and J. Rushen. 2006. Calves' behaviour during nursing is affected by feeding motivation and milk availability. Appl. Anim. Behav. Sci. 101:264-275.

De Paula Vieira, A., V. Guesdon, A. M. de Passillé, M. A. G. von Keyserlingk, and D. M. Weary. 2008. Behavioural indicators of hunger in dairy calves. Appl. Anim. Behav. Sci. 109:180-189.

Haley, D. B., J. Rushen, I. J. H. Duncan, T. M. Widowski, and A. M. de Passillé. 1998a. Effects of resistance to milk flow and the provision of hay on nonnutritive sucking by dairy calves. J. Dairy Sci. $81: 2165-2172$.

Haley, D. B., J. Rushen, I. J. H. Duncan, T. M. Widowski, and A. M. de Passillé. 1998b. Butting by calves, Bos taurus, and rate of milk flow. Anim. Behav. 56:1545-1551.

Hart, B. L. 1988. Biological basis of the behavior of sick animals. Neurosci. Biobehav. Rev. 12:123-137.

Jasper, J., and D. M. Weary. 2002. Effects of ad libitum milk intake on dairy calves. J. Dairy Sci. 85:3054-3058.

Jensen, M. B., and M. Budde. 2006. The effects of milk feeding method and group size on feeding behaviour and cross-sucking in grouphoused dairy calves. J. Dairy Sci. 89:4778-4783.

Johnson, R. W. 2002. The concept of sickness behaviour: A brief chronological account of four key discoveries. Vet. Immunol. Immunopathol. 87:443-450.

Jung, J., and L. Lidfors. 2001. Effects of amount of milk, milk flow and access to a rubber teat on cross-sucking and non-nutritive sucking in dairy calves. Appl. Anim. Behav. Sci. 72:201-213.

Kleinbaum, D. G. 1996. Survival Analysis-A Self-Learning Text. Springer Verlag, New York, NY.

Lidfors, L. M., P. Jensen, and B. Algers. 1994. Suckling in free-ranging beef cattle - Temporal patterning of suckling outs and effects of age and sex. Ethology 98:321-332.

Littell, R. C., G. A. Miliken, W. W. Stroup, and R. S. Wolfinger. 2006. SAS System for Mixed Models. SAS Inst. Inc., Cary, NC.

Martin, P., and P. Bateson. 2007. Measuring Behaviour-An Introductory Guide. 3rd ed. Cambridge University Press, Cambridge, UK.

Nielsen, B. L. 1999. On the interpretation of feeding behaviour measures and the use of feeding rate as an indicator of social constraints. Appl. Anim. Behav. Sci. 63:79-91.

Senn, M., S. Gross-Lüem, H. Leuenberger, and W. Langhans. 2000. Meal patterns and meal-induced metabolic changes in calves fed milk ad lib. Physiol. Behav. 70:189-195.

Stephens, D. B. 1975. Effects of gastric loading on the sucking response and voluntary milk intake in neonatal piglets. J. Comp. Physiol. Psychol. 882:796-805.

Svensson, C., and M. B. Jensen. 2007. Identification of diseased calves by use of data from automatic feeders. J. Dairy Sci. 90:994-997.

Weary, D. M., J. M. Huzzey, and M. A. G. von Keyserlingk. 2009. Using behavior to predict and identify ill health in animals. J. Anim. Sci. 87:770-777. 